\title{
Synthesis, characterization, and thermo-mechanical properties of copper-loaded apatitic calcium phosphates
}

\author{
Marta Galera Martínez, Doan Pham Minh*, Elsa Weiss-Hortala, Ange Nzihou and \\ Patrick Sharrock \\ Université de Toulouse, Mines Albi, CNRS, Centre RAPSODEE, Campus Jarlard, Albi cedex 09, \\ F-81013, France
}

\begin{abstract}
Copper is well known as a classical transition metal used in heterogeneous catalysis. In this study, copper-loaded apatitic calcium phosphates were prepared using incipient wetness impregnation (IWI) and ionic exchange (IE) methods. The interaction between copper precursor (copper nitrate trihydrate, $\left.\mathrm{Cu}\left(\mathrm{NO}_{3}\right)_{2} \cdot 3 \mathrm{H}_{2} \mathrm{O}\right)$ and apatitic calcium phosphate $(\mathrm{CaP})$ depended strongly on the preparation method and the content of copper-loaded. Using IE, copper(II) cations $\left(\mathrm{Cu}^{2+}\right)$ were incorporated in the apatitic structure of $\mathrm{CaP}$. The content of copper(II) cations seemed to be limited at about $2.2 \mathrm{wt} . \%$. Calcination at $400{ }^{\circ} \mathrm{C}$ had no influence on the solids obtained by the IE method. Using IWI, the deposition of a theoretical copper content of $2 \mathrm{wt} . \%$ led to the incorporation of copper(II) cations in the apatitic structure of $\mathrm{CaP}$ by IE with $\mathrm{Ca}^{2+}$, despite the low quantity of aqueous solvent used. Therefore the resulting product was similar to that obtained by IE. When the theoretical copper content rose to $20 \mathrm{wt} . \%$, the entire amount of copper precursor molecules were largely deposited, which resulted in the formation of copper oxide particles $(\mathrm{CuO})$ after air calcination at $400{ }^{\circ} \mathrm{C}$. Thermo-mechanical analysis study showed that the presence of copper oxide did not modify the thermal shrinkage of the initial calcium phosphate. On the other hand, thermal shrinkage was much more important in the case of $\mathrm{CaP}$ substituted with copper(II) cations.
\end{abstract}

Keywords: apatite; copper; ionic exchange; incipient wetness impregnation; thermo-mechanical analysis

\section{Introduction}

Calcium hydroxyapatite (Ca-HA), with the stoichiometric formula $\mathrm{Ca}_{10}\left(\mathrm{PO}_{4}\right)_{6}(\mathrm{OH})_{2}$, belongs to apatitic family. This mineral has the advantage of thermal stability, insolubility in water, high stability under reducing and oxidizing conditions, and to be able to accept many ions into its structure.[1,2] Thus, Ca-HA-based materials can be used in a wide variety of applications such as biomaterial engineering [3]; chromatography column fillers for the analysis of proteins [4]; treatment processes to remove toxic heavy metals from contaminated soils [5]; wastewater [6,7]; fly ashes [8]; backfill for nuclear waste repositories [9]; and catalysis.[10,11]

In heterogeneous catalysis, Ca-HA-based materials can be used in a wide range of reactions.[12-16] Ca-HA can catalyze itself different chemical reactions, thanks to its 
interesting physico-chemical properties, particularly the presence of both acidic and basic sites on its surface.[17] It can also be used as a support for the dispersion of other active phases, which are usually metals or metal oxides.[14,18,19] With specific surface areas up to $100 \mathrm{~m}^{2} \mathrm{~g}^{-1}$, the deposition of the metal or metal oxide on the surface of $\mathrm{Ca}-\mathrm{HA}$ can be carried out by classical methods such as incipient wetness impregnation (IWI).[20] Small clusters of metal or metal oxide are expected to form on the surface of the support. In addition, the excellent cationic exchange capacity of Ca-HA offers a particular route for the insertion of different divalent cations on its surface. In this case, it could be assumed that the active metal exists in cationic form, so at atomic scale. Thus, different physico-chemical, and therefore catalytic, properties of the composite might be expected, depending on the preparation method used.

We report in this paper the physico-chemical properties of copper-doped Ca-HA composites, which were prepared by two different routes, namely, ion exchange (IE) and IWI. Different characterization methods were used in order to understand the deposition and/or incorporation of copper on the surface of Ca-HA. This helps to optimize, in the next step, the use of copper-doped Ca-HA composites in the appropriate catalytic applications, since copper-based catalysts are found to be active in different catalytic processes.[21,22]

\section{Materials and methods}

\subsection{Preparation of apatitic calcium phosphates powder}

Calcium carbonate powder (98wt.\%, Fisher Scientific) and orthophosphoric acid (85 wt.\% in water, Merck) were used as received for the preparation of apatitic calcium phosphate. The choice of these starting reactants was based on their wide availability and low cost in comparison with classical reactants, such as calcium nitrate, calcium chloride, and alkali orthophosphate salts which require extensive washing of the resulting alkali salts from the calcium phosphate precipitate to obtain a pure product. In fact, in the previous work, Pham Minh et al. [23] showed that apatitic calcium phosphates starting from calcium carbonate and orthophosphoric acid had the same reactivity as Ca-HA synthesized from water soluble reactants, for the removal of lead(II) in an aqueous solution.

For the synthesis of Ca-HA, $100 \mathrm{~g}$ of calcium carbonate and $400 \mathrm{~g}$ of deionized water were introduced into a 1.2 L Pyrex batch reactor. Afterwards, $69.2 \mathrm{~g}$ of orthophosphoric acid (density of $1.71 \mathrm{~g} \mathrm{~mL}^{-1}$ ) was pumped at the rate of $1 \mathrm{~mL} \mathrm{~min}^{-1}$. The homogeneity of the reaction mixture was assured by a two-blade mixer ( $400 \mathrm{rpm})$. The reaction was kept at ambient conditions for $48 \mathrm{~h}$. After $48 \mathrm{~h}$, the product was filtered and dried overnight at $105^{\circ} \mathrm{C}$ in an isotherm oven, then calcined at $400{ }^{\circ} \mathrm{C}$ for $2 \mathrm{~h}$ to avoid all further evolution of the solid. The resulting solid powder was labeled CaP-ini, which was used for all further preparation of copper-doped apatitic calcium phosphates.

\subsection{Copper deposition}

Using IE, $7.5 \mathrm{~g}$ of CaP-ini were put into $300 \mathrm{~mL}$ of copper nitrate trihydrate $\left(\mathrm{Cu}\left(\mathrm{NO}_{3}\right)_{2} \cdot 3 \mathrm{H}_{2} \mathrm{O},>95 \mathrm{wt} . \%\right.$, Fisher Scientific) solution of know concentration under stirring at $350 \mathrm{rpm}$. After $4 \mathrm{~h}$ of contact, the suspension was filtered and the resulting solid was washed with permuted water and dried overnight at $105^{\circ} \mathrm{C}$. Using IWI, the required amount of $\mathrm{Cu}\left(\mathrm{NO}_{3}\right)_{2} \cdot 3 \mathrm{H}_{2} \mathrm{O}$ was dissolved in a volume of permuted water adapted to wet the outer and pore surfaces of CaP-ini. This solution was then added dropwise to $10 \mathrm{~g}$ of $\mathrm{CaP}$-ini at ambient temperature. At the completion of the addition, 
the powder was damp. Afterwards, the resulting solid was dried overnight at $105^{\circ} \mathrm{C}$. For both methods used, a half of dried solid was then calcined at $400{ }^{\circ} \mathrm{C}$ for $2 \mathrm{~h}$. In all cases, the concentration of copper nitrate solution was adjusted to have the theoretical contents of copper of 2 and $20 \mathrm{wt} . \%$ considering the deposition of copper on CaP-ini particles to be total. Samples were designated according to: (i) the method of preparation (IE or IWI); (ii) the theoretical percentage of $\mathrm{Cu}$ ( 2 or $20 \mathrm{wt} . \%)$; and (iii) the thermal treatment (DRY: only dried at $105^{\circ} \mathrm{C}$ (or uncalcined); or CAL: calcined at $400^{\circ} \mathrm{C}$ ). For example, CaP-IE-2-DRY corresponds to the solid prepared by IE method for obtaining theoretically $2 \mathrm{wt} . \%$ of copper, which was only dried at $105^{\circ} \mathrm{C}$.

\subsection{Characterizations}

The contents of $\mathrm{Cu}$ in the powders were obtained by inductively coupled plasma-atomic emission spectrometry analysis (ICP-AES) using a HORIBA Jobin Yvon Ultima 2 following dissolution of samples in a mixture of $\mathrm{HCl}$ and $\mathrm{HNO}_{3}$ acids. Thermogravimetry analysis (TG) was performed using a TA Instrument SDT Q600 analyzer. Weighed portions of powder sample ranged from 20 to $25 \mathrm{mg}$. The analysis was carried out in the temperatures ranged from 25 to $1000^{\circ} \mathrm{C}$ with a heating rate of $5^{\circ} \mathrm{C} \mathrm{min}{ }^{-1}$ under the air flow rate of $100 \mathrm{~mL} \mathrm{~min}^{-1}$. Thermo-mechanical analysis (TMA) was carried out in a Setaram Setsys 16/18 with $5 \mathrm{~g}$ of constant load on the powder sample under air atmosphere with the heating rate of $10^{\circ} \mathrm{C} \mathrm{min}^{-1}$. X-ray diffraction (XRD) measurements were performed using a Phillips Panalytical X'pert Pro MPD diffractometer with $\mathrm{Cu}-\mathrm{K} \alpha$ $(1.543 \AA$ ) radiation source at $45 \mathrm{kV}$ and $40 \mathrm{~mA}$. The identification of crystalline phases was carried out by comparison with JCPDS database. Fourier transform infrared spectroscopy (FTIR) was carried out using a Shimadzu 8400 S spectrophotometer. The specific surface area was determined by nitrogen adsorption at $77 \mathrm{~K}$ using a Micromeritics Gemini Vacprep 061 with the BET model $\left(S_{\mathrm{BET}}\right)$, and the true density was measured by helium pycnometry (Micromeritics, Accupyc 1330). Scanning electron microscopy (SEM) observation was carried out with a Philips XL30 FEG microscope.

\section{Results}

\subsection{Copper deposition}

The contents of copper in the uncalcined and calcined solid products are reported in Figure 1. For the samples prepared by IE, the contents of copper analyzed by ICP-AES technique were of 1.43 and $2.22 \mathrm{wt} . \%$ for CaP-IE-2-DRY and CaP-IE-20-DRY samples, respectively. Those of the corresponding calcined samples, CaP-IE-2-CAL and CaP-IE-20-CAL, were nearly similar, indicating that no mass change occurred during the calcination step. These results suggested that the ionic exchange (IE) between copper(II) and $\mathrm{Ca}(\mathrm{II})$ might approach the equilibrium and this method did not allow the deposition of higher contents of copper on CaP-ini. Similar results were found by Jemal et al. [24] for Ca-HA synthesized from soluble reactants $\left(\left(\mathrm{NH}_{4}\right)_{2} \mathrm{HPO}_{4}\right.$ and $\left.\mathrm{Ca}\left(\mathrm{NO}_{3}\right)_{2}\right)$, with copper dosages of $0-2.98$ wt.\%.

For the solid samples prepared by IWI, the copper contents were of 1.55 and 8.89 wt.\% for the uncalcined samples (CaP-IWI-2-DRY and CaP-IWI-20-DRY), respectively, and 2.04 and $13.48 \mathrm{wt} \%$ for calcined samples (CaP-IWI-2-CAL and CaP-IWI-20-CAL), respectively. So, larger amounts of copper could be deposited by this way on the CaP-ini support. The change in the content of copper after calcination step is discussed in Section 3.3 (thermal analysis). 

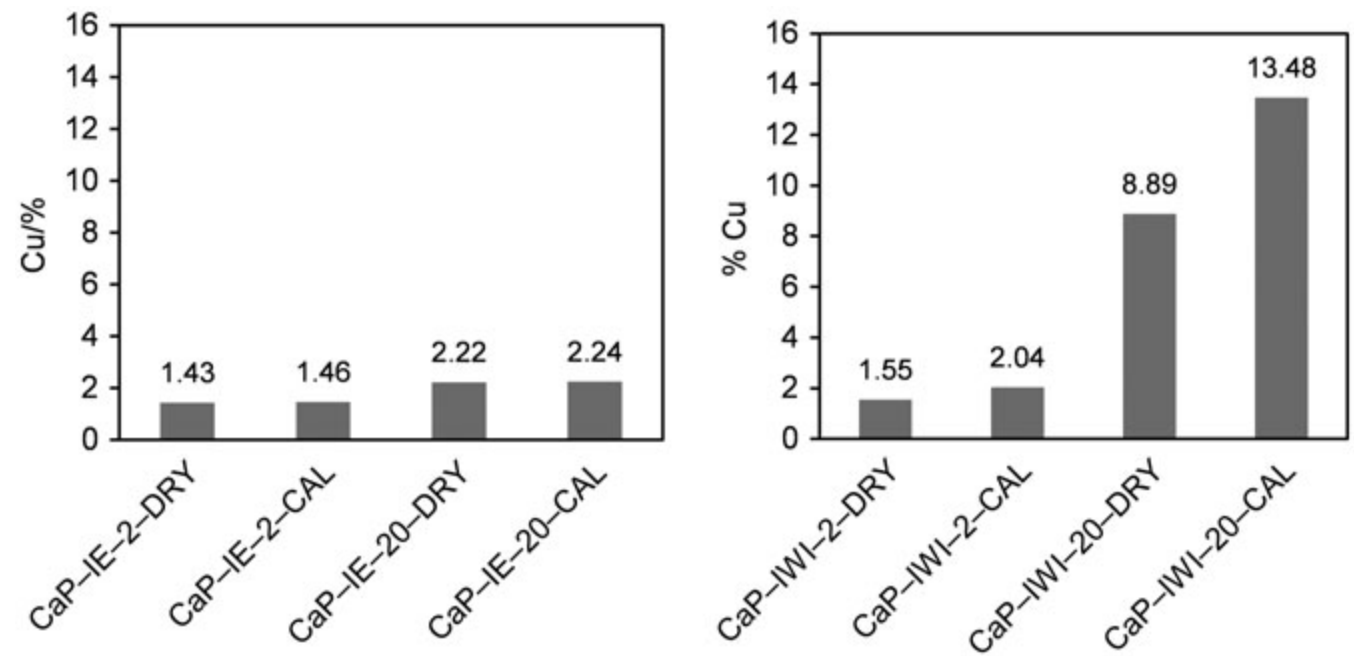

Figure 1. Copper contents of the solid products obtained by ICP-AES analysis.

\section{2. $X R D$}

Figure 2 shows the XRD patterns of CaP-ini and the samples prepared by IE. CaP-ini, which was previously calcined at $400{ }^{\circ} \mathrm{C}$, showed only diffraction peaks of the remaining calcium carbonate and poorly crystallized Ca-HA. For both uncalcined and calcined IE samples, no significant changes could be observed in comparison with the pattern of CaP-ini, despite the deposition of copper of 1.43-2.22 wt.\%. This deposition

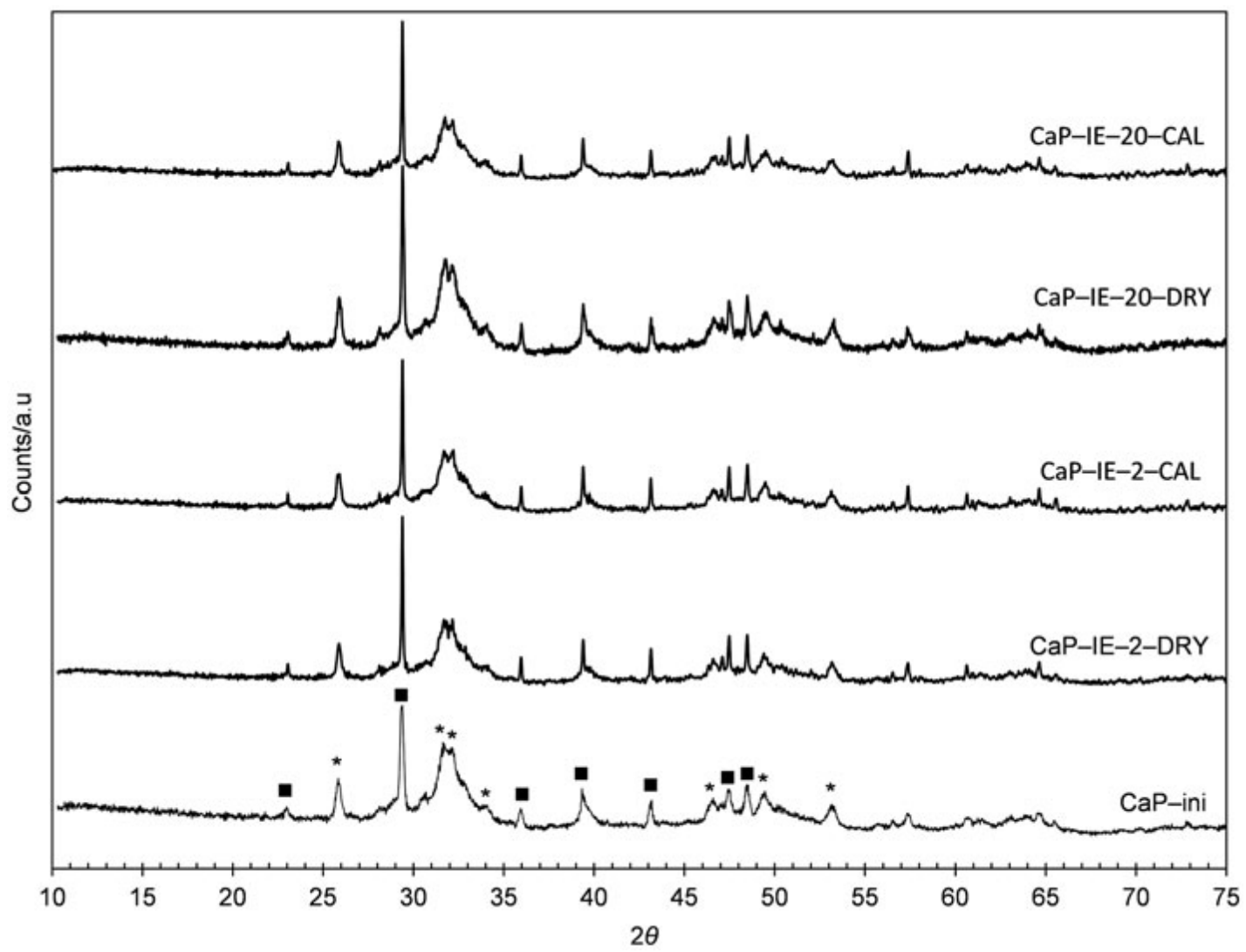

Figure 2. XRD patterns of samples prepared by IE; (*) calcite $\left(\mathrm{CaCO}_{3}\right) ;$ ( $\left.^{*}\right)$ calcium hydroxyapatite $\left(\mathrm{Ca}_{10}\left(\mathrm{PO}_{4}\right)_{6}(\mathrm{OH})_{2}\right)$. 
did not lead to detectable changes in the apatitic structure due to poor resolution of the d-spacings in low crystallinity solids. The content of copper-doped Ca-HA could be also insufficient to be observed by XRD analysis. Similar results were observed by Jemal et al. [24].

XRD patterns of CaP-ini and samples prepared by IWI are presented in Figure 3. Both CaP-IWI-2-DRY and CaP-IWI-2-CAL samples had similar XRD patterns in comparison to that of $\mathrm{CaP}$-ini. Only the remaining calcium carbonate and poorly crystallized Ca-HA were detected in these samples. This suggested that for the deposition of a theoretical content of copper of $2 \mathrm{wt} . \%$ by IWI, a cationic exchange might have taken place which led to the replacement of calcium(II) by copper(II). Consequently, copper(II) cations were inserted in the apatitic structure of Ca-HA and therefore were not transformed into other copper compounds under air calcinations, as observed for the samples prepared by IE method (Figure 2).

The change was distinct for CaP-IWI-20-DRY and CaP-IWI-20-CAL samples. Firstly, only trace amounts of the remaining calcium carbonate were observed. This indicated that the contact of CaP-ini with concentrated copper nitrate solution (initial $\mathrm{pH}$ of 2.1) led to the dissolution of calcium carbonate by acid attack, as observed previously.[23] Secondly, copper(II) hydroxynitrate $\left(\mathrm{Cu}_{2}(\mathrm{OH})_{3} \mathrm{NO}_{3}\right)$ was found as the principal crystalline phase of deposited copper in CaP-IWI-20-DRY. This phase was formed by the thermal decomposition of copper nitrate under air drying at $105^{\circ} \mathrm{C}$.[25] The calcination under air atmosphere at $400^{\circ} \mathrm{C}$ led to the transformation of copper(II)

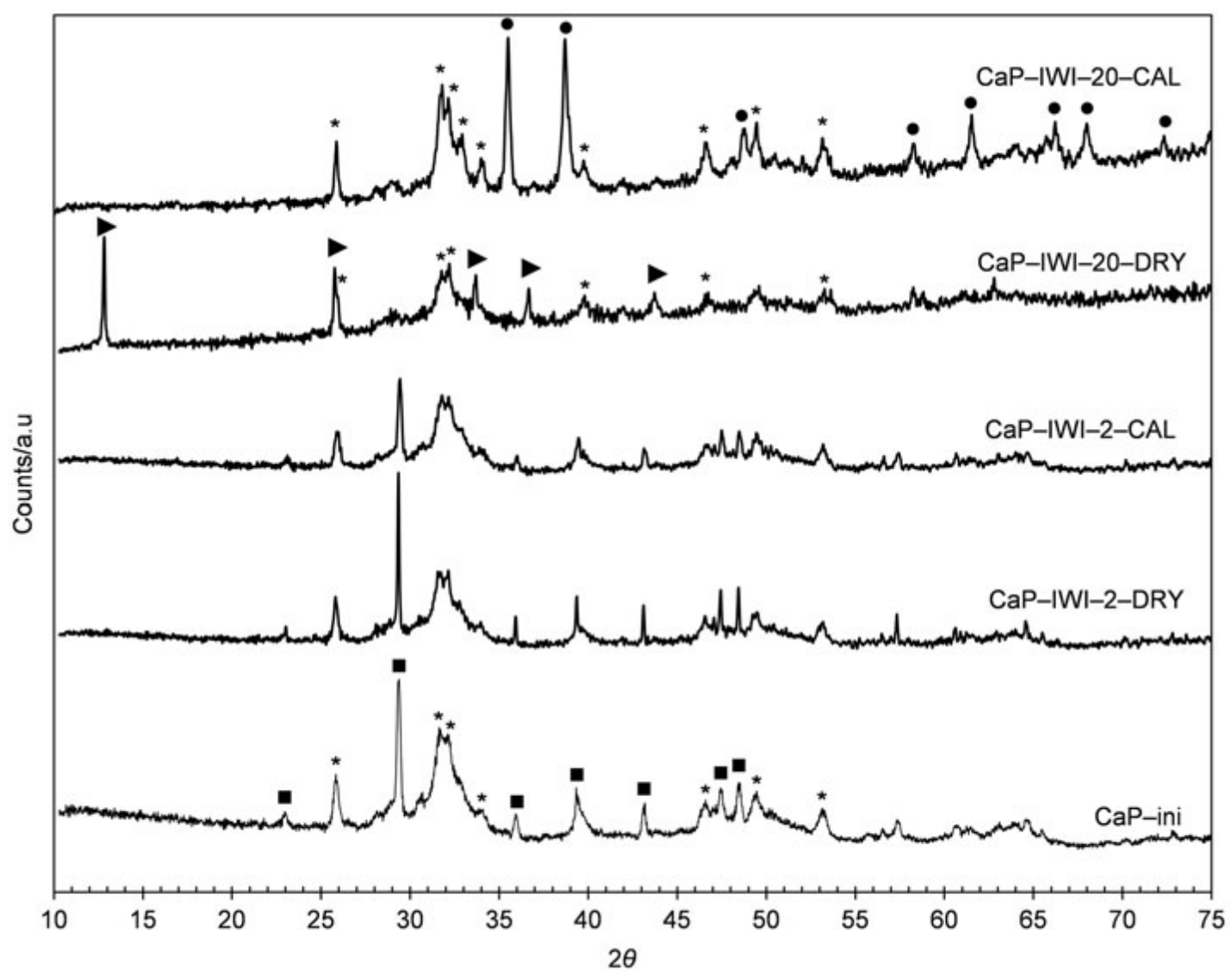

Figure 3. XRD patterns of samples prepared by IWI; (*) calcite $\left(\mathrm{CaCO}_{3}\right)$; (*) calcium hydroxyapatite $\left(\mathrm{Ca}_{10}\left(\mathrm{PO}_{4}\right)_{6}(\mathrm{OH})_{2}\right) ;(\bullet)$ copper(II) hydroxynitrate $\left(\mathrm{Cu}_{2}(\mathrm{OH})_{3} \mathrm{NO}_{3}\right) ;(\bullet)$ tenorite $(\mathrm{CuO})$. 
hydroxynitrate into tenorite $(\mathrm{CuO})$.[25] Finally, Ca-HA was the principal calcium phosphate found in these samples.

\subsection{Thermogravimetry analysis}

Thermal behavior of the solid products was investigated using TG. Figure 4 shows the derivative thermogravimetry (DTG) curves of the copper-doped samples, in comparison with that of the initial support (CaP-ini). All samples prepared by IE (Figure 4(A) and (C)) showed similar DTG curves compared to that of CaP-ini. In fact, in the temperature range of $25-400{ }^{\circ} \mathrm{C}$, there was only a slight weight loss at about $100^{\circ} \mathrm{C}$, which corresponded to the removal of surface moisture. This explained that the calcination at $400{ }^{\circ} \mathrm{C}$ had no effect on CaP-IE-2-DRY, as observed in XRD analysis. The next slight weight loss at $400-470{ }^{\circ} \mathrm{C}$ was attributed to the dehydration of dicalcium phosphate anhydrous (DCPA, $\left.\mathrm{CaHPO}_{4}\right)$ to form calcium pyrophosphate $\left(\mathrm{Ca}_{2} \mathrm{P}_{2} \mathrm{O}_{7}\right)$.[26] This weight loss was not intense, indicating the presence of small amounts of DCPA. The major weight loss at
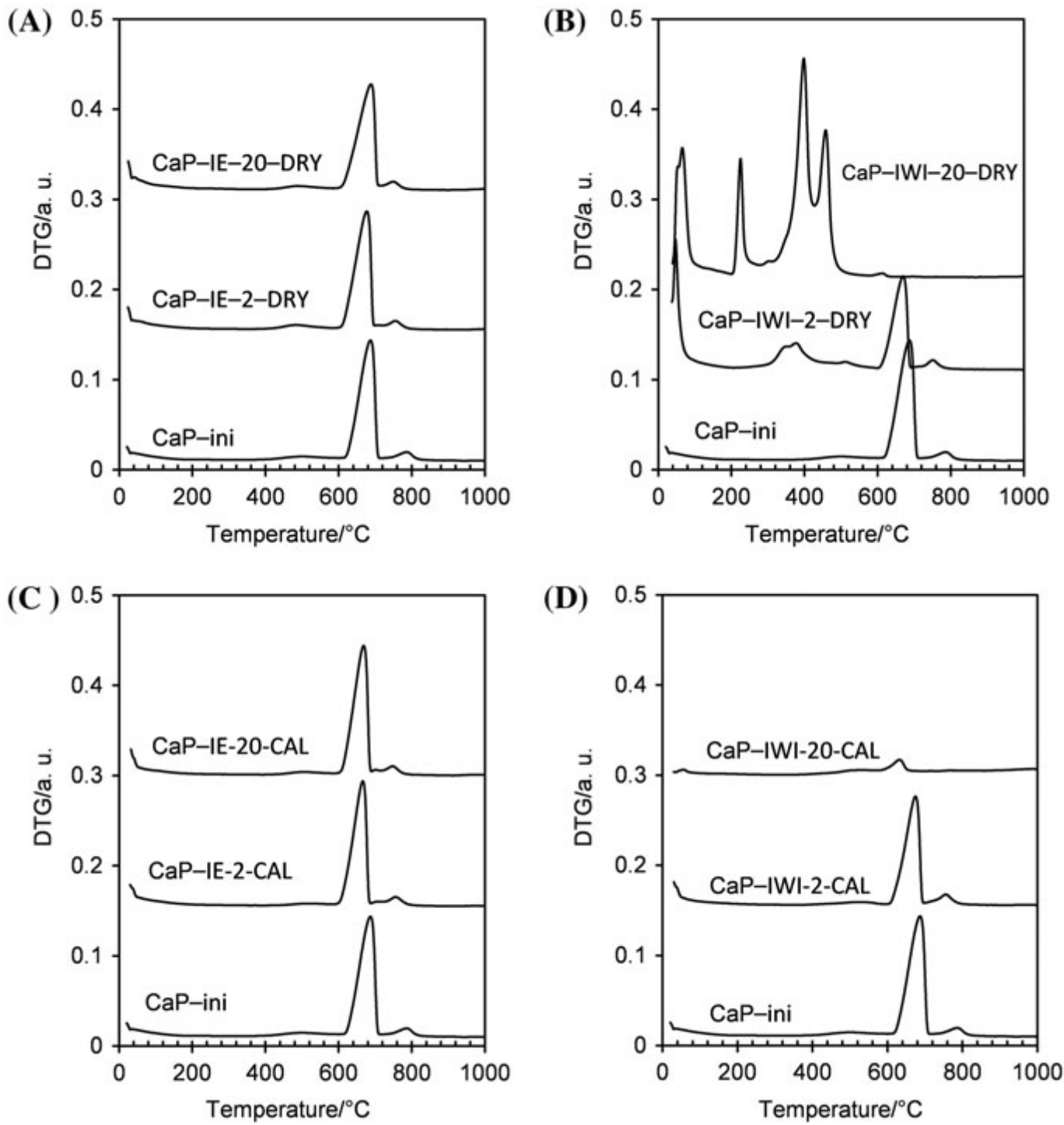

Figure 4. DTG curves of calcined (A and B) and uncalcined (C and D) samples, in comparison with that of CaP-ini. 
$600-710^{\circ} \mathrm{C}$ corresponded to the decarbonation of the remaining calcium carbonate, present in CaP-ini.[23] The last weight loss at $720-820^{\circ} \mathrm{C}$ could be attributed to the decarbonation of calcium carbonate apatite (CAP).[23] However, the partial replacement of calcium(II) by copper(II) caused a slight displacement in the $\mathrm{DTG}_{\max }$ (temperature at maximum DTG signals) of this peak from 786 to $754^{\circ} \mathrm{C}$ in both cases (Figure 4(A) and (C)).

The thermal behaviors of the samples prepared by IWI method were much more different from each other. For CaP-IWI-2-DRY sample (Figure 4(B)), an intense peak at about $40-90^{\circ} \mathrm{C}$ was observed, which must be due to the dehydration of the hydrated copper salts, which was previously impregnated on CaP-ini support.[25] Although the content of aqueous solvent used in the IWI method was low, cationic exchange took place which caused the displacement of $\mathrm{DTG}_{\max }$ of CAP decarbonation, as observed previously. The remaining calcium carbonate seemed to be stable for this sample meaning that acid attack did not significantly take place. Its intensity decreased in comparison with that of CaP-ini support, because of the deposition of copper salt, which increased the total weight of the solid. A new peak appeared at $300-440{ }^{\circ} \mathrm{C}$ which could be attributed to the decomposition of nitrate anions $\left(\mathrm{NO}_{3}^{-}\right)$. [27] In fact, IWI led to the deposition of nitrate anions on the surface of CaP-ini and under thermal effect, these anions decomposed into nitrogen dioxide $\left(\mathrm{NO}_{2}\right)$ and oxygen $\left(\mathrm{O}_{2}\right)$.

For CaP-IWI-20-DRY sample (Figure 4(B)), the strong DTG signal at $40-90{ }^{\circ} \mathrm{C}$ indicated the presence of hydrated copper salts. During acid attack of the concentrated solution of copper nitrate $(\mathrm{pH}$ of 2.1), the decarbonation of the remaining calcium carbonate and CAP took place and there were only trace amounts of carbonate left after drying. Three net DTG signals were observed, with $\mathrm{DTG}_{\max }$ at 222,395 and $457^{\circ} \mathrm{C}$. They were the characteristic peaks for the thermal decomposition of copper(II) hydroxynitrate $\left(\mathrm{Cu}_{2}(\mathrm{OH})_{3} \mathrm{NO}_{3}\right)$,[27] which confirmed again the XRD results (Figure 3). This explained also the change in the content of copper before and after calcinations step, observed by ICP-AES analysis in Figure 1.

Figure 4(D) shows the DTG curves of calcined IWI samples. The calcination at $400{ }^{\circ} \mathrm{C}$ allowed all dehydration reactions and the decomposition of nitrate and copper salts. Thus, only weak DTG signals of the decarbonation of remaining calcium carbonate and CAP were observed.

\subsection{FTIR}

FTIR spectra of CaP-ini and samples prepared by IE are shown in Figure 5. All spectra were similar to each other, before and after copper deposition and calcination at $400{ }^{\circ} \mathrm{C}$. The asymmetrical stretching $\left(v_{3}\right)$ and bending $\left(v_{4}\right)$ modes of $\mathrm{PO}_{4}^{3-}$ were observed at 1088 and 1024 , and 598 and $560 \mathrm{~cm}^{-1}$, respectively. The band at $960 \mathrm{~cm}^{-1}$ was assigned to the $\mathrm{PO}_{4}^{3-}$ symmetric stretching mode $\left(v_{1}\right)$. These peaks are characteristics for $\mathrm{PO}_{4}^{3-}$ groups present in an apatitic structure.[28] Two peaks at wavenumbers of 1420 and $880 \mathrm{~cm}^{-1}$ were attributed to the remaining calcium carbonate, which had only low intensities, despite its high contents in these samples as observed in Figure 4. In fact, previous study showed that the remaining calcium carbonate was usually covered by calcium phosphate layers [29] and therefore was only partially exposed to IR light. Carbonate groups inserted in CAP structure were characterized by the bi-modal peak at $1454 / 1405 \mathrm{~cm}^{-1}$, which confirmed the results of TG analysis. This bi-modal peak is characteristic for B-type CAP wherein $\mathrm{PO}_{4}^{3-}$ groups were replaced by $\mathrm{CO}_{3}^{2-}$ groups.[30] 

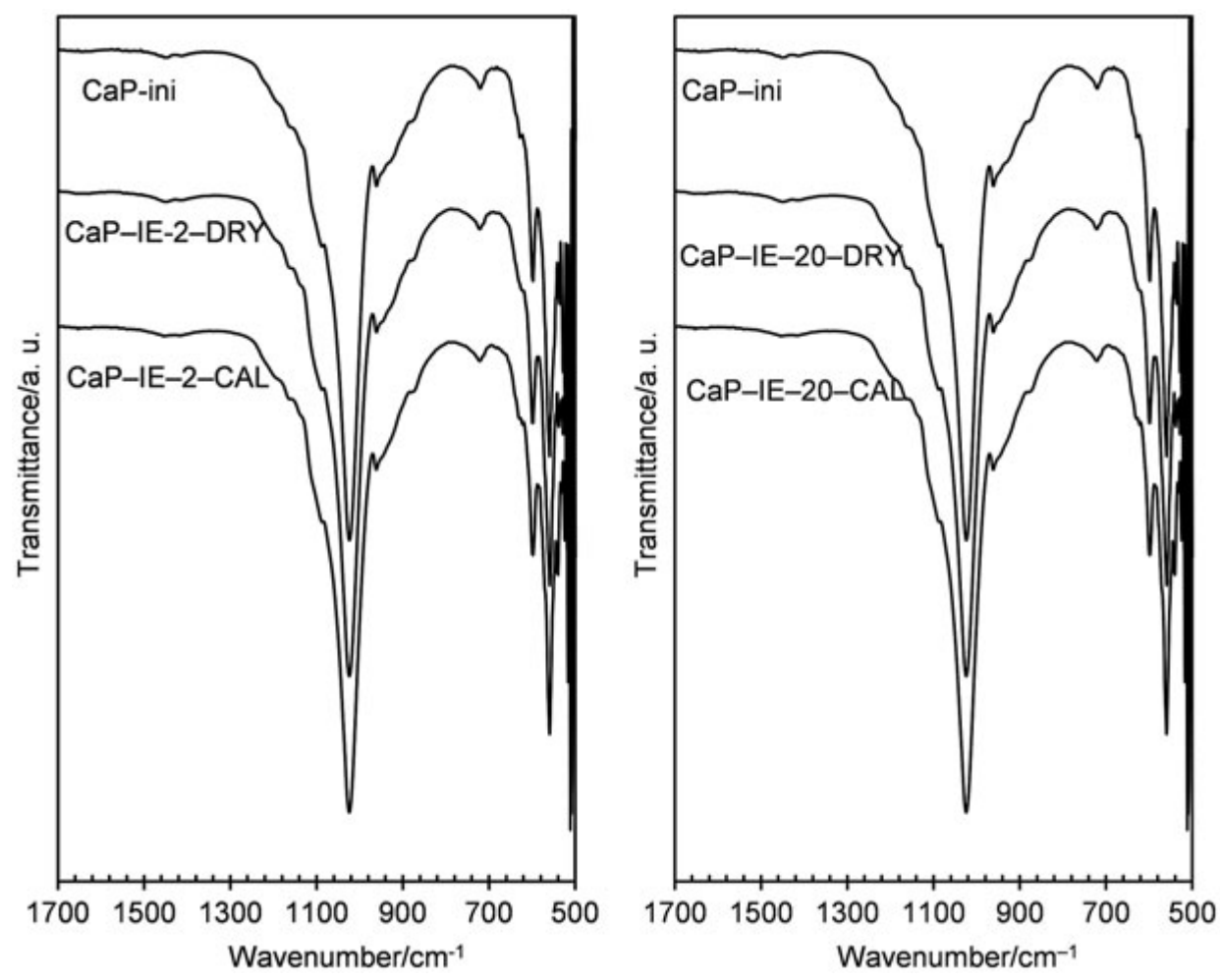

Figure 5. IR spectra of the initial support (CaP-ini) and samples prepared by IE.

Figure 6 shows FTIR spectra of samples prepared by IWI. Uncalcined samples had the stretching of $\mathrm{OH}^{-}$groups around $3500 \mathrm{~cm}^{-1}$. The shoulder at about $3400 \mathrm{~cm}^{-1}$ and the peak at $1650 \mathrm{~cm}^{-1}$ could be attributed to the stretching and bending modes of molecular water in hydrated copper salts. Classical bands of apatitic $\mathrm{PO}_{4}^{3-}$ groups at the wavenumbers of 1088, 1024, 960,598, $560 \mathrm{~cm}^{-1}$ were also observed for the CaP-IWI-2-DRY sample. In comparison with the CaP-ini support, the CaP-IWI-2-DRY sample had two other peaks at 1417 and $1350 \mathrm{~cm}^{-1}$, which are attributed to the $\mathrm{N}-\mathrm{O}$ bond vibration of nitrate groups.[31,32] On the other hand, the IR spectrum of CaP-IWI-20-DRY was completely different from those of CaP-ini and CaP-IWI-2-DRY. With high content of copper nitrate salts, it was possible that the initial calcium phosphate particles of CaP-ini support were covered by copper nitrate layers. Thus, different bands (1417, 1350, $1026 \mathrm{~cm}^{-1}$ ) of copper(II) hydroxynitrate could be observed,[33] which was in good agreement with XRD results. The band at $1026 \mathrm{~cm}^{-1}$ illustrated the bending vibration of $\mathrm{Cu}-\mathrm{O}-\mathrm{H}$ and those at 1417 and $1350 \mathrm{~cm}^{-1}$ corresponded to nitrate groups.

For calcined IWI samples, copper(II) hydroxynitrate was decomposed into copper oxide (Figure 3). Thus, apatitic calcium phosphates, remaining calcium carbonate and copper oxide were the main components of these samples. Their IR spectra were similar to that of CaP-ini. Bands of $\mathrm{HO}^{-}, \mathrm{PO}_{4}^{3-}$ and $\mathrm{CO}_{3}^{2-}$ groups, present in $\mathrm{Ca}-\mathrm{HA}, \mathrm{CAP}$ and remaining calcium carbonate, were observed and correspond to those already discussed above. Copper oxide did not show IR bands, as expected for metal oxides.

\subsection{Specific surface area $\left(S_{B E T}\right)$, true density, and SEM analyses}

The specific surface area $\left(S_{\mathrm{BET}}\right)$ and true density $(d)$ of the solids before and after copper deposition are reported in Table 1. For IE samples, the addition of copper to CaP-ini support did not lead to any notable change of $S_{\text {BET. }}$ On the other hand, a slight 

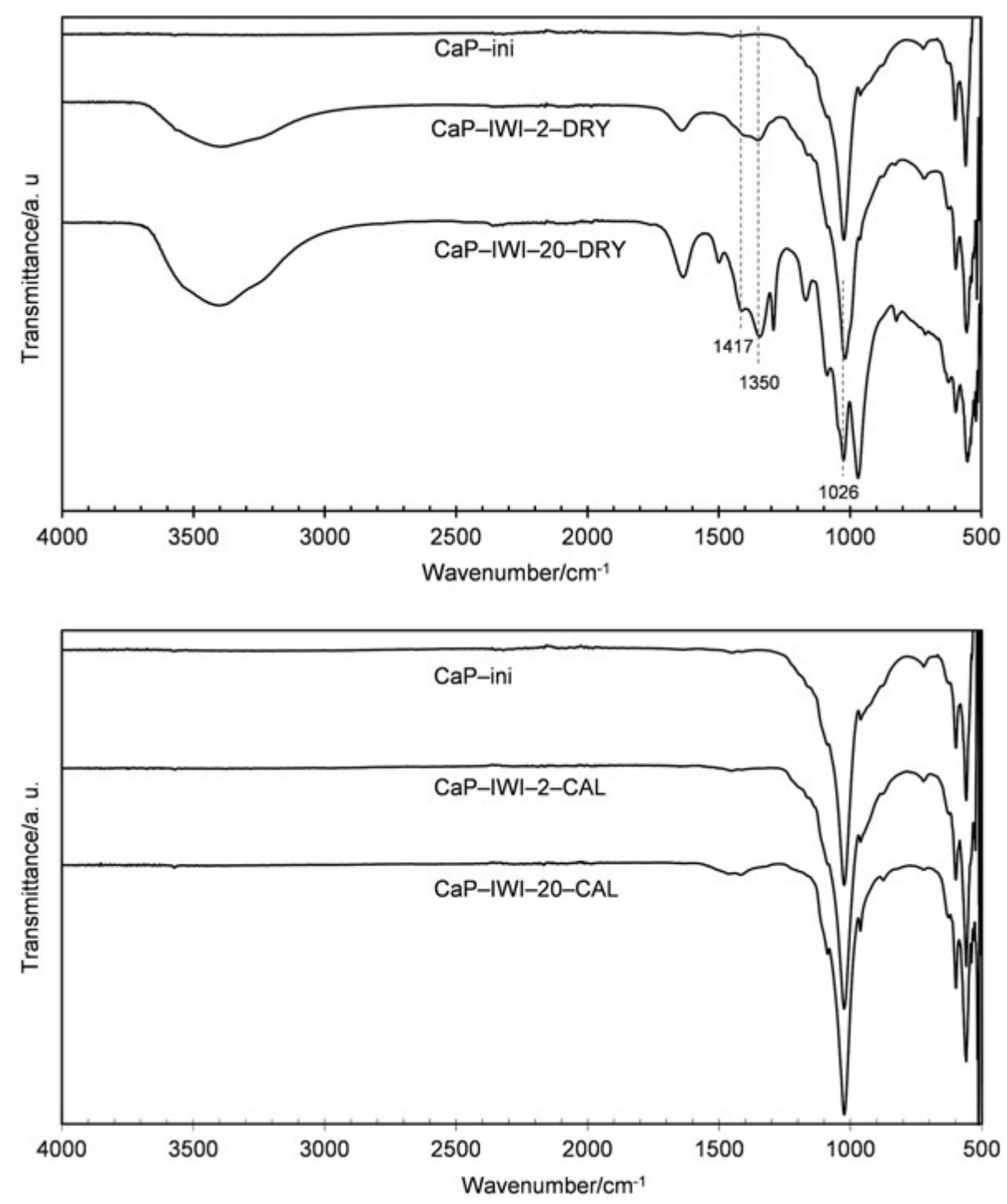

Figure 6. FTIR spectra of the initial support (CaP-ini) and samples prepared by IWI.

Table 1. Specific surface area $\left(S_{\mathrm{BET}}\right)$ and true density $(d)$ of the solids prepared by IE and IWI.

\begin{tabular}{lcc}
\hline Solid & $S_{\mathrm{BET}} / \mathrm{m}^{2} \mathrm{~g}^{-1}$ & $d / \mathrm{g} \mathrm{cm}^{-3}$ \\
\hline CaP-ini & 29 & 2.820 \\
CaP-IE-2-DRY & 33 & 3.016 \\
CaP-IE-2-CAL & 31 & 3.021 \\
CaP-IE-20-DRY & 33 & 3.010 \\
CaP-IE-20-CAL & 33 & 3.060 \\
CaP-IWI-2-DRY & 27 & 2.223 \\
CaP-IWI-2-CAL & 31 & 3.069 \\
CaP-IWI-20-DRY & 9 & 2.041 \\
CaP-IWI-20-CAL & 23 & 3.449 \\
\hline
\end{tabular}

increase of true density was observed. This change might be due to the substitution of $\mathrm{Ca}^{2+}$ by $\mathrm{Cu}^{2+}$, wherein the atomic weight of copper (63.546) is higher than that of calcium (40.078). 
For dry IWI samples, strong decrease of both true density and $S_{\mathrm{BET}}$ were observed. In fact, adsorption-desorption isotherm showed that CaP-ini support was a porous material with the porous volume equal to $0.25 \mathrm{~cm}^{3} \mathrm{~g}^{-1}$. We propose that the solidification of large $\mathrm{Cu}\left(\mathrm{NO}_{3}\right)_{2} \cdot 3 \mathrm{H}_{2} \mathrm{O}$ salt deposits led to the clogging of pores, resulting in an inaccessibility to pores, and therefore to the decrease of density and $S_{\mathrm{BET}}$. Following air calcination, the copper precursor was decomposed into copper oxide. This opened and freed the pores of the support which explained the true density and $S_{\mathrm{BET}}$ of calcined IWI samples compared to those of uncalcined IWI samples.

To enhance the arguments above for $S_{\mathrm{BET}}$ and true density results, SEM observations were performed for all solid products and some results are illustrated in Figure 7. CaP-ini support had particle sizes varying in wide range from $100 \mathrm{~nm}$ to $100 \mu \mathrm{m}$ (Figure 7(A2)). At higher magnification (Figure 7(A1)), the surface of particles seemed to be compact and particles of sheet-like structure could be observed which are usually
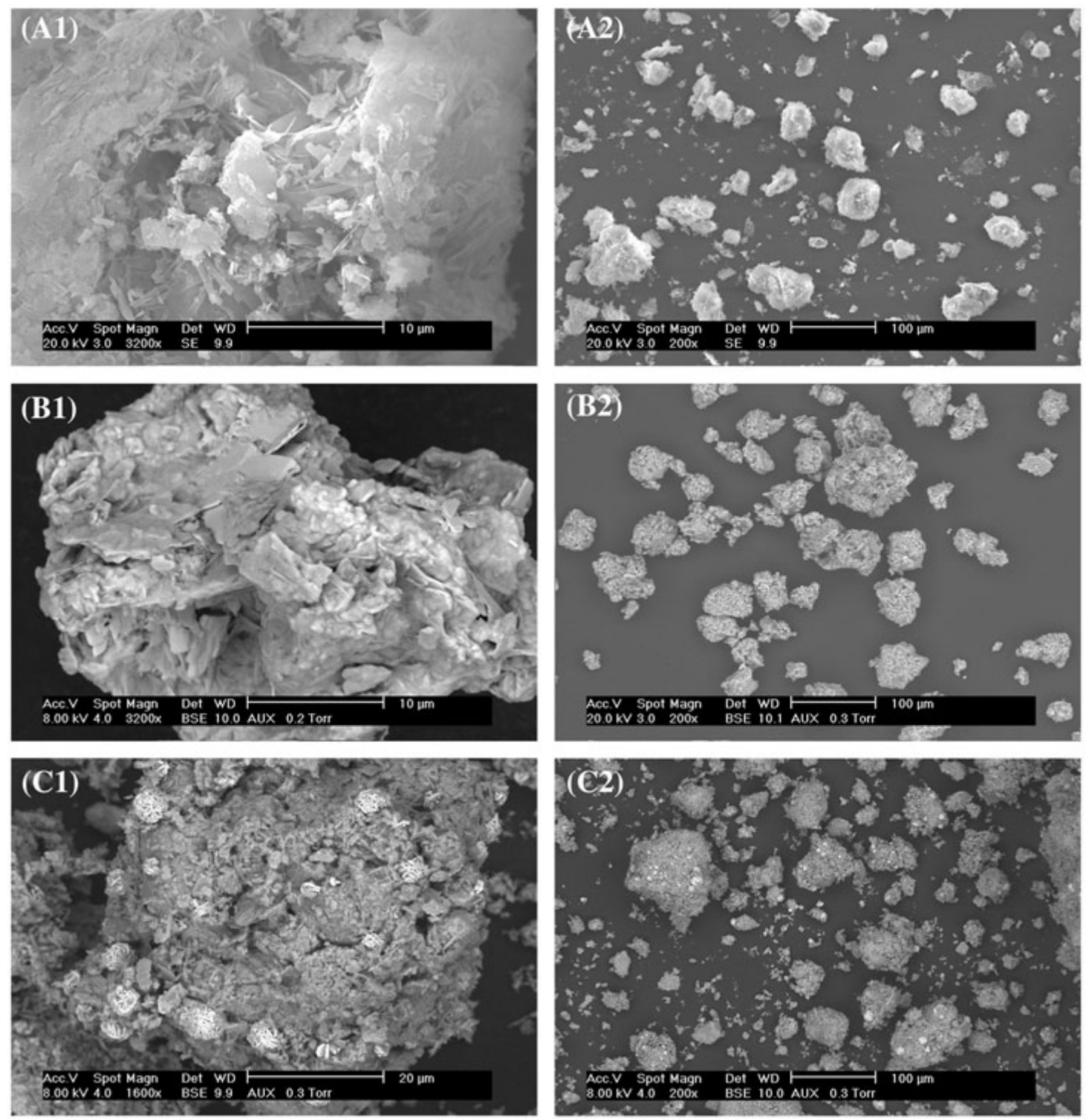

Figure 7. SEM images of CaP-ini support (A1, A2), CaP-IWI-20-DRY (B1, B2), and CaP-IWI20-CAL (C1, C2) samples. 
attributed to dicalcium phosphate dihydrate (DCPD, $\mathrm{CaHPO}_{4} \cdot 2 \mathrm{H}_{2} \mathrm{O}$ ) and dicalcium phosphate anhydrate (DCPA, CaHPO ${ }_{4}$ ).[26] Similar results were obtained for the solid products synthesized by IE or by IWI with the theoretical value of copper content of 2 wt.\%. Therefore, these results were not illustrated.

Distinct changes were observed for CaP-IWI-20-DRY (Figure 7(B1) and (B2)) and CaP-IWI-20-CAL (Figure 7(C1) and (C2)) samples. There was no notable change in particle sizes before and after calcination (Figure 7(B1) and (B2), respectively) compared to CaP-ini support (Figure 7(A1)). However, layers of copper precursor could be clearly observed for the uncalcined sample (B1). After calcination, particles of copper oxide could be also easily observed which had strong contrast (arrows).

\subsection{TMA analysis}

Catalytic processes using $\mathrm{Ca}-\mathrm{HA}$ and metal-loaded Ca-HA are usually performed at high temperature. For example, water gas shift reaction was carried out using $\mathrm{Au}-$ and $\mathrm{Ru}-\mathrm{loaded} \mathrm{Ca}-\mathrm{HA}$ at $100-400^{\circ} \mathrm{C}$.[18] Oxidative coupling of methane was performed on a lead containing $\mathrm{Ca}-\mathrm{HA}$ at $650-800^{\circ} \mathrm{C}$.[34] The reaction temperature is well known as an important parameter for the activity and selectivity of a catalyst. Knowledge of the thermomechanical behavior of Ca-HA based materials helps to better understand and design the appropriate catalytic reactor, and therefore to anticipate the effective use of Ca-HA-based materials in high temperature catalytic processes.

Figure 8 shows the TMA curves of CaP-ini support and copper-loaded Ca-HA with the theoretical value of copper content of $20 \mathrm{wt} . \%$. Below $550{ }^{\circ} \mathrm{C}$, the shrinkage was nearly negligible for all samples, except a small shrinkage of $-1 \%$ at about $110-180{ }^{\circ} \mathrm{C}$ for CaP-IWI-20-DRY sample. This must be due to the dehydration of copper precursor present in this sample. CaP-ini support and two samples prepared by IE (Figure 8(A)) had a small dilatation $(<1.6 \%)$ between 550 and $830^{\circ} \mathrm{C}$. Then, strong shrinkages took place during the temperature rise from 830 to $1000^{\circ} \mathrm{C}$ and the isothermal time at $1000^{\circ}$ C. After the isothermal time of $60 \mathrm{~min}$ at $1000^{\circ} \mathrm{C}$, shrinkage of $-9.8 \%$ was observed for CaP-ini. CaP-IE-20-DRY and CaP-IE-20-CAL samples showed higher shrinkages, which were of 18.8 and $21.3 \%$, respectively (Figure 8(A)). CaP-IWI-20-DRY and CaP-IWI-20-CAL samples had no dilatation in the temperatures range of $550-830^{\circ} \mathrm{C}$ and their shrinkages were similar to that of $\mathrm{CaP}$-ini support at the temperature higher than $830^{\circ} \mathrm{C}$ (Figure 8(B)).

Generally, thermal shrinkage is due to chemical reactions resulting in the formation of gas products or denser solid components and to the sintering phenomenon.[35] Figure 8(A) highlighted that the insertion of copper(II) in the apatitic structure of CaP-ini enhanced the thermal shrinkage. A reorganization of copper(II)-containing Ca-HA might take place to form denser solid phases, and/or the presence of copper(II) might promote the sintering of calcium phosphates present in CaP-ini. Supplementary characterizations are needed to better understand the role of copper(II) in this case. On the other hand, the deposition of copper oxide particles $(\mathrm{CuO})$ on the surface of CaP-ini had no notable influence on its thermal shrinkage in the temperature range used. 

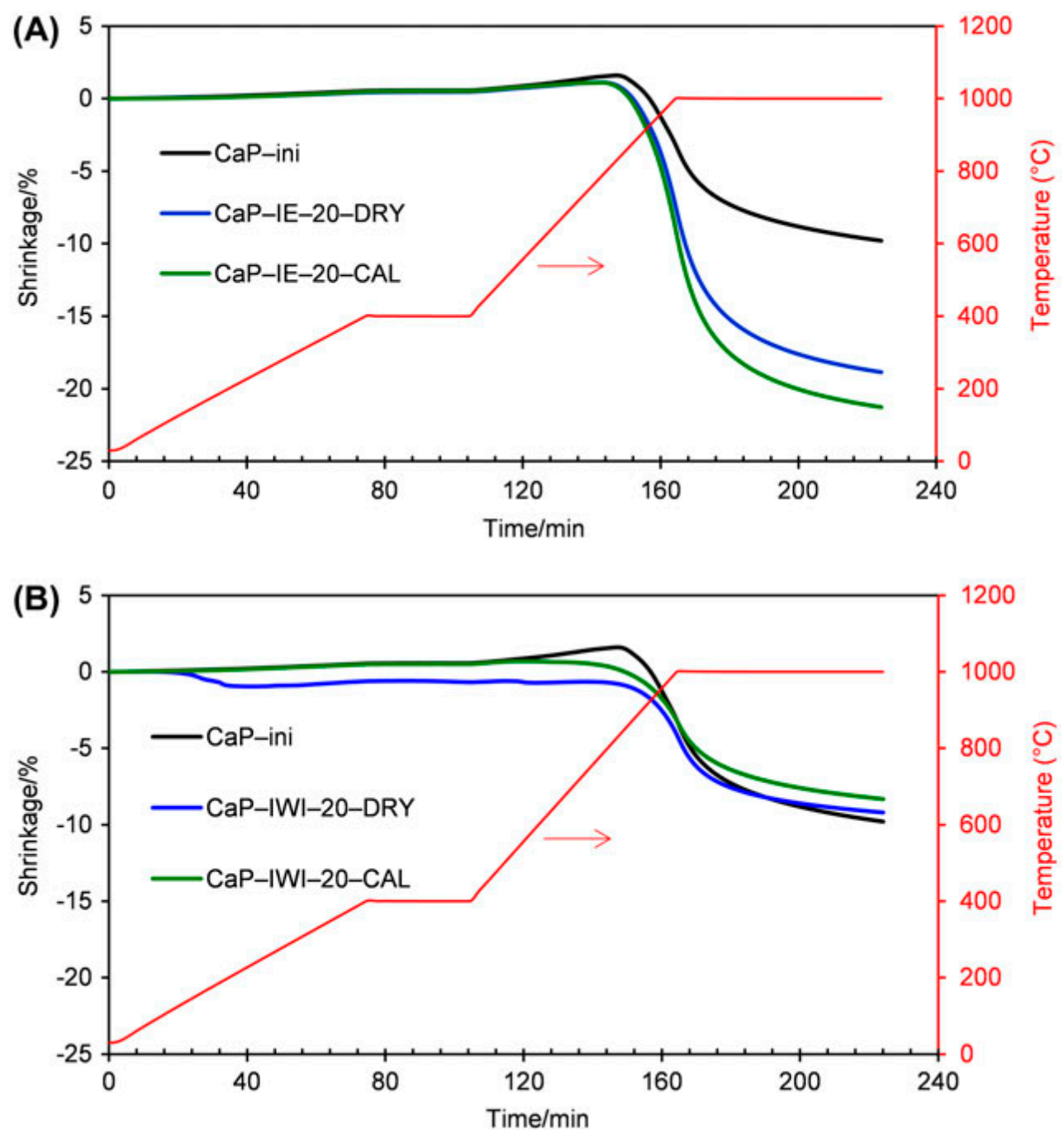

Figure 8. TMA analysis of IE (A) and IWI (B) samples prepared at the theoretical copper content of $20 \mathrm{wt} . \%$, compared to that of the initial support (CaP-ini). Thermal shrinkage is defined as $\left(L-L_{\mathrm{o}}\right) / L_{\mathrm{o}}$ or $\Delta L / L_{\mathrm{o}}$, where $L_{\mathrm{o}}$ is the initial length of sample and $L$ is the length of sample measured at temperature $T$ or time $t$.

\section{Conclusions}

Copper-loaded apatitic calcium phosphate was synthesized using IE and IWI methods. In the samples prepared by IE, copper(II) replaced calcium(II) leading to the displacement of the thermal decomposition of carbonate-containing apatite (CAP) to lower temperatures. For the exchange conditions used, the content of copper-loaded by IE method seemed to be limited at about $2.2 \mathrm{wt} . \%$ despite a higher quantity of copper cations available for the exchange (theoretical value of $20 \mathrm{wt} . \%$ ). The air calcination at $400{ }^{\circ} \mathrm{C}$ seemed to have no effect on the state and structure of components of IE samples.

The deposition of copper by IWI led to the formation of different solid products as a function of the quantity of copper precursor. For a theoretical value of $2 \mathrm{wt} . \%$ of copper loading, IE took place and seemed to be more important compared to the deposition of copper precursor molecules, which is expected for this method of preparation. Thus, XRD characterization of the corresponding calcined product did not show the presence of copper oxide. SEM observation did not also reveal the presence of copper oxide particles for this calcined sample. When higher copper content was 
loaded (theoretical value of $20 \mathrm{wt} . \%$ ), the deposition of copper precursor salts dominated and copper oxide resulted in the corresponding calcined product.

TMA of the solid products was also performed. The deposition of copper oxide particles did not lead to the notable change of thermal shrinkage compared to the initial support. On the other hand, the insertion of copper(II) into the apatitic structure of the initial support accelerated the thermal shrinkage. These results will be considered for our future works on the use of copper-loaded apatitic calcium phosphates in high temperature catalytic processes, in particular the thermo-conversion of methane and carbon dioxide.

\section{Acknowledgments}

The authors thank gratefully their colleagues at the RAPSODEE center, Christine Rolland, Nathalie Lyczko, for their technical help.

\section{References}

[1] Marchat D, Bernache-Assollant D, Champion E, Bêche E, Flamant G. Adsorption and incorporation of cadmium into a calcium hydroxyapatite. Adv. Sci. Technol. 2006;45:2055-2060.

[2] Sheha RR. Sorption behavior of $\mathrm{Zn}(\mathrm{II})$ ions on synthesized hydroxyapatites. J. Colloid Interface Sci. 2007;310:18-26.

[3] Lazic S, Zec S, Miljevic N, Milonjic S. The effect of temperature on the properties of hydroxyapatite precipitated from calcium hydroxide and phosphoric acid. Thermochim. Acta. 2001;374:13-22.

[4] Shepard SR, Brickman-Stone C, Schrimsher JL, Koch G. Discoloration of ceramic hydroxyapatite used for protein chromatography. J. Chromatogr. A. 2000;891:93-98.

[5] Boisson J, Ruttens A, Mench M, Vangronsveld J. Evaluation of hydroxyapatite as a metal immobilizing soil additive for the remediation of polluted soils. Part 1. Influence of hydroxyapatite on metal exchangeability in soil, plant growth and plant metal accumulation. Environ. Pollut. 1999;104:225-233.

[6] Fernane F, Mecherri MO, Sharrock P, Hadioui M, Lounici H, Fedoroff M. Sorption of cadmium and copper ions on natural and synthetic hydroxylapatite particles. Mater. Charact. 2008;59:554-559.

[7] Baillez S, Nzihou A, Bernache-Assolant D, Champion E, Sharrock P. Removal of aqueous lead ions by hydroxyapatites: equilibria and kinetic processes. J. Hazard. Mater. A. 2007;139:443-446.

[8] Nzihou A, Sharrock P. Calcium phosphate stabilization of fly ash with chloride extraction. Waste Manage. 2002;22:235-239.

[9] Moore RC, Gasser M, Awwad N, Holt KC, Salas FM, Hasan A, Hasan MA, Zhao H. Sorption of plutonium(VI) by hydroxyapatite. J. Radioanal. Nucl. Chem. 2005;263:97-101.

[10] Solhy A, Tahir R, Sebti S, Skouta R, Bousmina M, Zahouily M, Larzek M. Efficient synthesis of chalcone derivatives catalyzed by re-usable hydroxyapatite. Appl. Catal., A. 2010;374:189-193.

[11] Resende NS, Nele M, Salim VMM. Effects of anion substitution on the acid properties of hydroxyapatite. Thermochim. Acta. 2006;451:16-21.

[12] Ya-Ping S, Hai-Yan F, Ding-lin Z, Rui-Xiang L, Hua C, Xian-Jun L. Complete hydrogenation of quinoline over hydroxyapatite supported ruthenium catalyst. Catal. Commun. 2010;12:188-192.

[13] Liptáková B, Hronec M, Cvengrošová Z. Direct synthesis of phenol from benzene over hydroxyapatite catalysts. Catal. Today. 2000;61:143-148.

[14] Boukha Z, Kacimi M, Pereira MFR, Faria JL, Figueiredo JL, Ziyad M. Methane dry reforming on Ni loaded hydroxyapatite and fiuoroapatite. Appl. Catal., A. 2007;317:299-309.

[15] Wuyts S, De Vos DE, Verpoort F, Depla D, De Gryse R, Jacobs A. A heterogeneous Ruhydroxyapatite catalyst for mild racemization of alcohols. J. Catal. 2003;219:417-424. 
[16] Masuyama Y, Nakajima Y, Okabe J. Environmentally-benign palladium(II)-exchanged hydroxyapatite-catalyzed allylic alkylation of allyl methyl carbonate in water. Appl. Catal., A. 2010;387:107-112.

[17] Tsuchida T, Kubo J, Yoshioka T, Sakuma S, Takeguchi T, Ueda W. Reaction of ethanol over hydroxyapatite affected by Ca/P ratio of catalyst. J. Catal. 2008;259:183-189.

[18] Venugopal A, Scurrell MS. Hydroxyapatite as a novel support for gold and ruthenium catalysts: behaviour in the water gas shift reaction. Appl. Catal., A. 2003;245:137-147.

[19] Cheikhi N, Kacimi M, Rouimi M, Ziyad M, Liotta LF, Pantaleo G, Deganello G. Direct synthesis of methyl isobutyl ketone in gas-phase reaction over palladium-loaded hydroxyapatite. J. Catal. 2005;232:257-267.

[20] Achchar M, Lamonier C, Ezzamarty A, Lakhdar M, Leglise J, Payen E. New apatite-based supports prepared by industrial phosphoric acid for HDS catalyst synthesis. C.R. Chim. 2009;12:677-682.

[21] Rajeev R, Devi KA, Abraham A, Krishnan K, Krishnan TE, Ninan KN, Nair CGR. Thermal decomposition studies. Part 19. Kinetics and mechanism of thermal decomposition of copper ammonium chromate precursor to copper chromite catalyst and correlation of surface parameters of the catalyst with propellant burning rate. Thermochim. Acta. 1995;254:235-247.

[22] Masuyama Y, Yoshikawa K, Suzuki N, Hara K, Fukuoka A. Hydroxyapatite-supported copper(II)-catalyzed azide -alkyne [3+2] cycloaddition with neither reducing agents nor bases in water. Tetrahedron Lett. 2011;52:6916-6918.

[23] Pham Minh D, Sebei H, Nzihou A, Sharrock P. Apatitic calcium phosphates: synthesis, characterization and reactivity in the removal of lead(II) from aqueous solution. Chem. Eng. J. 2012;198-199:180-190.

[24] Jemal J, Tounsi H, Chaari K, Petitto C, Delahay G, Djemel S. NO reduction with $\mathrm{NH}_{3}$ under oxidizing atmosphere on copper loaded hydroxyapatite. Appl. Catal., B. 2012;113114:255-260.

[25] Morozov IV, Znamenkov KO, Korenev YM, Shlyakhtin OA. Thermal decomposition of $\mathrm{Cu}\left(\mathrm{NO}_{3}\right)_{2} \cdot 3 \mathrm{H}_{2} \mathrm{O}$ at reduced pressures. Thermochim. Acta. 2003;403:173-179.

[26] Pham Minh D, Lyczko N, Sebei H, Nzihou A, Sharrock P. Synthesis of calcium hydroxyapatite from calcium carbonate and different orthophosphate sources: a comparative study. Mat. Sci. Eng., B. 2012;177:1080-1089.

[27] Ghose J, Kanungo A. Studies on the thermal decomposition of $\mathrm{Cu}\left(\mathrm{NO}_{3}\right)_{2} \cdot 3 \mathrm{H}_{2} \mathrm{O}$. J. Therm. Anal. 1981;20:459-462.

[28] Pham Minh D, Tran ND, Nzihou A, Sharrock P. One-step synthesis of calcium hydroxyapatite from calcium carbonate and orthophosphoric acid under moderate conditions. Ind. Eng. Chem. Res. 2013;52:1439-1447.

[29] Verwilghen C, Chkir M, Rio S, Nzihou A, Sharrock P, Depelsenaire G. Convenient conversion of calcium carbonate to hydroxyapatite at ambient pressure. Mat. Sci. Eng., C. 2009;29:771-773.

[30] Lafon JP, Champion E, Bernache-Assollant D. Processing of AB-type carbonated hydroxyapatite $\mathrm{Ca}_{10-\mathrm{x}}\left(\mathrm{PO}_{4}\right)_{6-\mathrm{x}}\left(\mathrm{CO}_{3}\right)_{\mathrm{x}}(\mathrm{OH})_{2-\mathrm{x}-2 \mathrm{y}}\left(\mathrm{CO}_{3}\right)_{\mathrm{y}}$ ceramics with controlled composition. J. Eur. Ceram. Soc. 2008;28:139-147.

[31] da Cunha MCPM, De Souza JPI, Nart FC. Reaction pathways for reduction of nitrate ions on platinum, rhodium, and platinum-rhodium alloy electrodes. Langmuir. 2000;16:771-777.

[32] Chaika MY, Bulavina EV, Solyanikova AS, Kravchenko TA, Seredin PV. The mechanism of electroreduction of nitrate ions on a hybrid electrode nanodispersed copper-MK-40 membrane. Russ. J. Electrochem. 2012;48:212-217.

[33] Niu H, Yang Q, Tang K. A new route to copper nitrate hydroxide microcrystals. Mat. Sci. Eng., B. 2006;135:172-175.

[34] Park TJ, Suh DJ, Lee KY, Korea Institute of Science and Technology. Preparation of $\mathrm{Pb}$-substituted hydroxyapatite catalyst and use in oxidative coupling of methane. United State patent US 5,877,387. 1999 Mar 2.

[35] Pham Minh D, Galera Martínez M, Nzihou A, Sharrock P. Thermal behavior of apatitic calcium phosphates synthesized from calcium carbonate and orthophosphoric acid or potassium dihydrogen orthophosphate. J. Therm. Anal. Calorim. 2013;12:1145-1155. 